\title{
Role of Parenting Styles in Determining Self-Esteem and Loneliness among Undergraduate Students
}

\author{
Garima Nayak $^{1 *}$, Arshiya Kochar ${ }^{2}$
}

\section{ABSTRACT}

A child's personality and behaviour has always been a reflection of his/her upbringing and the values that the parents have given him or her. Each parent has their own way to deal with their children. Parenting style has often seem to affect a child's personality traits like persistence, trust, forgiveness, or attributes like self-efficacy, identity formation, or behaviour like aggressiveness, etc. To further explore the role of parenting style, this study aims to see its role in determining self-esteem and loneliness. To fulfill this purpose, a sample of 100 undergraduate students was drawn from Delhi University, and parenting style, self-esteem and loneliness were measured. The findings revealed a positive relationship between parenting styles and loneliness and a negative relationship between parenting styles and self-esteem.

Keywords: Parenting Style, Self-Esteem, Loneliness.

Developmental psychology is one of the branches of psychology that is a scientific approach to study how children and adults develop over time. Most of the developmental theories focus on childhood period as it is the period during an individual's lifespan when the most changes occur. For the purpose of explaining development, this discipline takes into account the contribution of both nature and nurture. While nature may help explain most of the physical development of an individual, nurture seems to have major effects on how an individual's personality is shaped at a later stage.

Parents form the most immediate environment of the child. Developmental psychologists have long been interested in how parents impact a child's development. Some children raised in dramatically different environments can later grow up to have remarkably similar personalities. However, keeping in mind the nature-nurture debate, one can also say, children who share a home and are raised in the same environment can grow up to have astonishingly different

\footnotetext{
${ }^{1}$ Research Scholar, (Hons.) Psychology, Kamala Nehru College, University of Delhi, India

${ }^{2}$ Research Scholar, (Hons.) Psychology, Sri Aurobindo College (Eve), University of Delhi, India

*Responding Author

(C) 2016 G Nayak, A Kochar; licensee IJIP. This is an Open Access Research distributed under the terms of the Creative Commons Attribution License (http://creativecommons.org/licenses/by/2.0), which permits unrestricted use, distribution, and reproduction in any Medium, provided the original work is properly cited.
} 


\section{Role of Parenting Styles in Determining Self-Esteem and Loneliness among Undergraduate Students}

personalities. There are no set guidelines for the parents to follow while raising their child, thus each parent has his/her own way of raising the child. The parenting styles play an important role in the development of a child over the time. Therefore, this paper aims to study the role of parenting styles in determining loneliness and self-esteem, two very important aspects of an individual's personality.

\section{Parenting Styles}

Baumrind (1971) conceptualized parenting styles as a parent's attitude towards their children, the values they attach to their own parenting and the practices they resort to when dealing with their children. These can be categorised as authoritative (high demand and high responsiveness), authoritarian (high demand and low responsiveness), permissive (low demand and high responsiveness) and indifferent or neglectful (low demand and low responsiveness) (Baumrind, 1971). It must also be understood that these parenting styles build the affective environment in which the child develops the perception of her/his parents' behaviour.

In 1993, researchers Harris and Brown examined whether parental indifference and abuse in childhood had any specific link to anxiety or disorder later on in their adult life. Results of the study indicated that indeed, parental indifference and abuse did significantly raise the likelihood of depression and/or anxiety in adulthood. Parents constitute the foundation upon which the child is guided from a state of guiding them infantile dependence into autonomy. Hence, it is evident that the parenting styles adopted by the parents have both an immediate as well as lasting effect on the child's social functioning as well as personality. Freud and Erikson heavily emphasised on the importance and the impact of the relationship between the individual and their caregivers on their subsequent 'normal' development, both in terms of personality and later development in multiple areas- more specifically, social.

Children with authoritative parents are more competent than children raised with other parenting styles. Such children are also seemed to have low levels of well-being, but high levels of achievement. Steinberg et al. found that children with neglectful parents showed the lowest levels of both well-being and achievements. Many researches also show how parenting style affects different aspects of a child's personality like self-esteem (Hosogi et al., 2012).

\section{Self Esteem}

In terms of sociology and psychology, self-esteem constitutes of a person's overall evaluation of her or his self-worth, value, importance, or capabilities (Myers \& Myers, 1992). Rosenberg described self-esteem as a favourable or unfavourable attitude towards the self. It is a resultant of the judgement we make of our own self, as well as the consequent attitude we have towards our own self. In other words, self-esteem is nothing but the extent to which one values, approves of or appreciates him or herself. 


\section{Role of Parenting Styles in Determining Self-Esteem and Loneliness among Undergraduate Students}

Among adolescents, and especially students, a low self-esteem can propagate feelings of alienation as a consequence of the belief that they are inferior to their peers, and hence, experience feelings of being 'left behind', even though this idea might be completely falsifiable. Taken to extreme lengths, it might even give rise to depression and detaching themselves from their social circuits out of fear of possible rejection and/or failure. It's important to note that selfesteem is not only determined by 'feeling good about oneself' psychologically, but the image we have of our physical appearance also plays a major role. Owing to society's stringent views of 'beauty', this has become an especially important concern.

Interactions between a child and the parents play a major role in shaping her/ his self esteem. Supportive and encouraging parenting results in high self-esteem wherein the child is actively encouraged to initiate exploratory behaviour. According to previous researches, family factor is one of an important external factor that influences self-esteem (Growe, 1980; Buri et al., 1987; Buri et al., 1992). Therefore the present study focuses on parenting styles as an important external factor.

\section{Loneliness}

Asher and Paquette (2003) pointed out that loneliness by itself is not pathological, but is more of an internal emotional state. Nonetheless, high levels of loneliness may lead to negative outcomes, especially for adolescents and students. It is important to note that loneliness does not indicate a lack of companionship, but it depends entirely on our subjective assessment of our relationships, and whether we feel emotionally connected to those around us. Hence, it comes as no surprise that loneliness can distort our perception about our existing relationships, making us withdraw and alienate ourselves from them. Consequently, those around us might get hesitant to approach us, further aggravating our feelings of loneliness.

The relationship between low self-esteem and loneliness becomes clear when adolescents with a low self-esteem experience feelings of alienation and detachment because of their belief that they are inferior in their peer group strata. In turn, feelings of loneliness too, might often give way to low self-esteem issues. An individual feeling lonely may attribute the cause of her /his loneliness to 'not being good enough'.

Loneliness has a strong connection to parenting styles, hence, making it possible to trace it back to childhood. Neglectful parenting can result in the child feeling lonely, because they do not receive the attention and affection they require from their parents. This leads the child to try and develop social relations on their own accords, failing at which they begin to harbour feelings of loneliness (Matthew J. Miller). It then, comes as no surprise that neglectful parenting cripples the child's ability to form healthy social bonds, since she/he lacks any sense of warmth or attachment, and as a result is unable to attribute the same to her/his own relationships. Healthy parenting involves constantly encouraging the child to take active part in activities and build 
friendships. It also requires giving adequate time to the child so she/he can have healthy and fruitful experiences. Absence of parental involvement leads to a lack of social development and isolation. Thus this study focuses on he influence of parenting styles on loneliness.

\section{Present Study}

The present study aims to study self-esteem and loneliness, as a result of parenting styles, among the undergraduate students of Delhi University. Both Freud's and Erikson's emphasize the role of parents in the development of one's personality. Parenting styles have seemed to determine various aspects of one's personality such as trust, forgiveness, gratitude, hope, depression etc. Thus this study focuses on the relationship between parenting styles and self-esteem and loneliness.

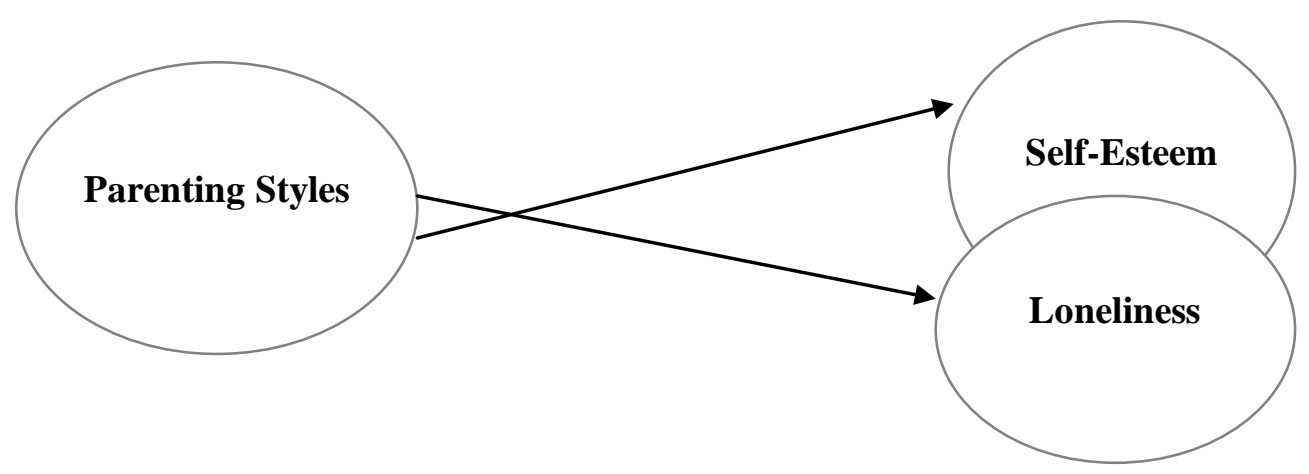

Figure 1: Effect of Parenting Styles on Self-Esteem and Loneliness

\section{METHOD}

\section{Participants}

The data was collected from 100 undergraduate students of Delhi University, out of which 52 were females and 48 were males. The sample was drawn using Random Sampling Method. The socio-economic status of the participants was held constant, and also information about their family was also taken like number of family members and number of siblings.

\section{Tools Used}

Three tools were used for data collection. They are as follows

1. Measure of Parental Styles- This scale was developed by Parker et al. (1997). It is a selfassessment tool that is used to measure perceived parenting style across three different measures i.e. Indifference, Overcontrol and Abuse. The measure is 'retrospective', meaning that adults (over 16 years) complete the measure for how they remember their parents during their first 16 years. The measure is to be completed for both mothers and fathers separately. This tool has 15 items each for mothers and fathers, and is rated on a 3-point Likert scale.

2. UCLA Loneliness Scale- This scale was developed by Russell in 1996. It is a 20-item scale designed to measure one's subjective feelings of loneliness as well as feelings of social isolation, rated on a 4-point Likert scale, where 1= "Never" and 4= "Often". 
Role of Parenting Styles in Determining Self-Esteem and Loneliness among Undergraduate Students

3. State Self Esteem Scale- This scale was developed by Heatherton \& Polivy (1991). It is a 20item scale that is subdivided into 3 components of self-esteem, i.e. performance self-esteem, social self-esteem, and appearance self-esteem. All items are answered using a 5-point scale (1= not at all, 2= a little bit, 3= somewhat, 4= very much, 5= extremely).

\section{RESULT}

Mean and Standard Deviation of all the variables used in the study were found out, as shown in Table 1. Pearson's Product Moment Correlation (r) was calculated amongst all variables as shown in Table 2.

Table 1: Mean and Standard Deviation of all the variables

\begin{tabular}{|l|l|l|}
\hline Variable & Mean & Std. Deviation \\
\hline Indifference (Mother) & 2.0500 & 3.99589 \\
\hline Indifference (Father) & 2.4800 & 3.47423 \\
\hline Abuse (Mother) & 1.5700 & 2.67897 \\
\hline Abuse (Father) & .8700 & 1.72126 \\
\hline Over-control (Mother) & 3.9700 & 2.49223 \\
\hline Over-control (Father) & 3.0100 & 2.42252 \\
\hline Father's Total & 6.3600 & 6.78013 \\
\hline Mother's Total & 7.5900 & 8.06300 \\
\hline Loneliness Total & 41.7100 & 7.32409 \\
\hline Performance Self- Esteem & 25.5000 & 4.47327 \\
\hline Social Self-Esteem & 26.0100 & 5.36260 \\
\hline Appearance Self-Esteem & 19.3300 & 4.63421 \\
\hline Self-Esteem Total & 70.8400 & 11.89153 \\
\hline
\end{tabular}

$\mathrm{N}=100$

Table 2: Pearson's Product Moment Correlation among the variables

\begin{tabular}{|l|l|l|l|l|l|}
\hline Variables & Loneliness & Performance SE & Social SE & Appearance SE & $\begin{array}{l}\text { Self- } \\
\text { Esteem }\end{array}$ \\
\hline Indifference (M) & $.257^{* *}$ & $-.356^{* *}$ & $-.267^{* *}$ & -.159 & $-.316^{* *}$ \\
\hline Indifference (F) & .075 & $-.423^{* *}$ & $-.492^{* *}$ & $-.262^{* *}$ & $-.483^{* *}$ \\
\hline Abuse (M) & $.249^{*}$ & $-.415^{* *}$ & $-.365^{* *}$ & -.182 & $-.392^{* *}$ \\
\hline Abuse (F) & .152 & $-.297^{* *}$ & $-.403^{* *}$ & -.138 & $-.347^{* *}$ \\
\hline Over-control (M) & .169 & $-.398^{* *}$ & $-.212^{*}$ & $-.227^{*}$ & $-.334^{* *}$ \\
\hline Over-control (F) & $.264^{* *}$ & $-.368^{* *}$ & $-.341^{* *}$ & $-.226^{*}$ & $-.380^{* *}$ \\
\hline Total (F) & .171 & $-.424^{* *}$ & $-.476^{* *}$ & $-.250^{*}$ & $-.471^{* *}$ \\
\hline Total (M) & $.262^{* *}$ & $-.437^{* *}$ & $-.319^{* *}$ & $-.209^{*}$ & $-.390^{* *}$ \\
\hline
\end{tabular}

$\mathrm{N}=100 ;{ }^{* *} p<.01, * p<.05$ (M=Mother; $\mathrm{F}=$ Father)

(c) The International Journal of Indian Psychology, ISSN 2348-5396 (e)| ISSN: 2349-3429 (p) | 68 
A perusal of Table 2 shows that Father's Parenting Style (Indifference, Abuse and Over-control) as a whole shares a significantly negative correlation with Self-Esteem $(* * p<0.1)$ and a positive but non-significant relationship with Loneliness $(r=0.171)$. Mother's Parenting Style (Indifference, Abuse and Over-control) share a significantly positive correlation with Loneliness and a significantly negative correlation with Self-Esteem $\left({ }^{* *} p<01\right)$.

\section{DISCUSSION}

This study aimed to study the relationship between parenting styles and self-esteem, and parenting styles and loneliness among the undergraduate students of the University of Delhi. Previous researches have taken into consideration numerous variables while explaining this phenomenon. Variables like problem solving, academic self-efficacy, sense of belongingness, perceived social support, etc. have found to be related to different parenting styles in different ways. In this study we explored the relationship between parenting styles and self-esteem, and parenting styles and loneliness.

The extent of literature shows that different parenting styles shape a child's personality differently. Previous researches have tried to investigate the connection between parenting styles and personal traits. Most studies show that there's a link between self-esteem and parenting styles that can be further explored. There appears to be a correlation between certain parenting styles and higher or lower levels of self-esteem in children (Hosogi et al., 2012). In this study, we used Measure of Parental Style (MOPS) (Parker et al., 1997) that is a self-assessment tool, retrospective in nature, and it covers three parenting styles i.e. Indifference, Abuse and Overcontrol for both father and mother differently. To measure self-esteem, State Self-Esteem Scale (Heatherton \& Polivy (1991) was used, and it has 3 components i.e. Performance SE, Social SE and Appearance SE. The results show a significantly negative correlation between Father's and Mother's Parenting Style and self-esteem as a whole $(r=-0.471 ; r=-0.390 * * p<.01)$. The findings indicate that in the given sample, both the mother and the father adopted an indifferent and overcontrolling parenting style that led children to grow up with low self-esteem. To measure loneliness, the UCLA Loneliness Scale (Russell, 1996) was used. The result showed that overcontrolling and indifferent parenting style leads to an increased feeling of loneliness among the undergraduates. A significantly positive correlation was found between the parenting styles of mother and father with loneliness $(* * p<.01)$.

Thus the findings of the current study contribute to our understanding of possible effects of different parenting styles on self-esteem and loneliness among individuals. These findings support the general research pertaining to relationships between parenting style and self-esteem (Growe, 1980; oh, 2004) and parenting style and loneliness. Parents who are indifferent or overcontrolling towards their children are not usually warm or supportive which might make the children feel isolated and lonely. If parents are warm, supportive and involved in their children's 
life, this might instill feelings of self-worth in them and make them recognizer their self-worth, value and importance (Myers \& Myers, 1992).

\section{Acknowledgments}

The author appreciates all those who participated in the study and helped to facilitate the research process.

\section{Conflict of Interests}

The author declared no conflict of interests.

\section{REFERENCES}

Bednar '00, Kiley L. (2000). Loneliness and Self-Esteem at Different Levels of the Self. Honors Projects. Paper 20.

Driscoll, L.C. (2013). Parenting Styles and Self-Esteem. Scripps Senior Theses. Paper 155.

McLeod, S. A. (2012). Developmental Psychology. Retrieved from www.simplypsychology.org/developmental-psychology.html

Parker, G., Roussos, J., Hadzi-Pavlovic, D., Mitchell, P., Wilhelm, K. and Austin, M-P. (1997). The Development of a Refined Measure of Dysfunctional Parenting and Assessment of Its Relevance in Patients with Affective Disorders. Psychological Medicine 27, 1193-1203.

Sailor, D. H. (2004). Supporting Children in their Home, School and Community. p. 158-159.

Turkmen, M. \& Demirli, A. (2011). The Predictive Value of Gender, Perceived Parenting Styles and Loneliness in Determining Students' Dispositional and State Hope Level. Journal of Theory and Practice in Education, 7 (2):347-363.

Vanhalst, J., Luyckx, K., Scholte, R.H., Engels, R. C. \& Goossens, L. (2013). Low Self Esteem as a Risk Factor for Loneliness in Adolescence: Perceived-But Not Actual- Social Acceptance as an Underlying Mechanism. Abnormal Child Psychology 41 (7): 1067-81.

Wolff, J. (2000). Self-Esteem: The Influence of Parenting Styles. Edith Cowan University.

Zakeri, H. \& Karimpour, M. (2011). Parenting Styles and Self-Esteem. Procedia-Social and Behavioural Sciences 29 (2011) 758-761: Elsevier.

How to cite this article: G Nayak, A Kochar (2016), Role of Parenting Styles in Determining

Self-Esteem and Loneliness among Undergraduate Students, International Journal of Indian Psychology, Volume 4, Issue 1, No. 69, ISSN:2348-5396 (e), ISSN:2349-3429 (p), DIP:18.01.009/20160401, ISBN:978-1-365-45447-9 